\title{
INTERFACES ENTRE FONÉTICA E FONOLOGIA: CONCEITOS, PESQUISAS, PERSPECTIVAS
}

\author{
Izabel Christine Seara \\ Giovana Ferreira-Gonçalves \\ Mirian Rose Brum-de-Paula \\ (Organizadoras)
}

Esta edição temática reúne seis artigos dedicados a estudos fonético-fonológicos. Todas as contribuições contam com a participação de dois ou três autores, geralmente oriundos de diferentes IES. As pesquisas reportadas possuem características peculiares: são realizadas em equipes, necessitam de ambiente laboratorial, empregam programas específicos de processamento de dados, são experimentais e, sempre que possível, buscam novas respostas a práticas de pesquisa e ensinoaprendizagem, ancoradas em ferramentas tecnológicas ainda pouco exploradas na pesquisa linguística brasileira. A seguir, algumas considerações sobre cada um dos textos desse dossiê temático.

O primeiro artigo, intitulado Considerações sobre a aerodinâmica das vogais nasais do português brasileiro: a variedade florianopolitana, trata das vogais nasais plenas do português urbano falado em Florianópolis, apresentando resultados do cruzamento de dados acústicos e aerodinâmicos. Para tanto, além de análises acústicas, Izabel Seara, Fernando Pacheco e Angelique Amelot efetuaram análises aerodinâmicas, que são raras no contexto da pesquisa brasileira. Para comparar os dados obtidos com dois informantes nativos de Florianópolis, os pesquisadores precisaram lançar mão de resultados advindos de investigações do idioma francês, que possui estudos com viés aerodinâmico há mais tempo. Os parâmetros analisados combinaram a curva de fluxo aéreo nasal e o percentual de nasalidade. Eis as questões que os autores propõem responder: (i) Que padrões de fluxo nasal, captados pelo acelerador piezoelétrico e pelo microfone nasal, serão encontrados para as vogais nasais do PB falado em Florianópolis? (ii) Com relação aos momentos que compõem as vogais nasais, o que podemos dizer? (iii) Considerando-se os percentuais de nasalidade medidos a partir do acelerador piezoelétrico e do microfone nasal, quais serão os comportamentos observados? e (iv) As curvas de fluxo aéreo, provenientes do acelerador piezoelétrico e do 
microfone nasal, apresentariam diferenças em função da qualidade vocálica?

O texto seguinte, denominado Caracterização acústica da vogal átona final /e/ no português porto-alegrense e no espanhol uruguaio, propõe um estudo comparativo entre duas variedades: a variedade do português porto-alegrense e a variedade do espanhol montevideano. A investigação visou a contribuir tanto para o mapeamento dessas duas variedades como para fins de ensino e aprendizagem do Espanhol como Segunda Língua. O estudo contou com a participação de nativos monolíngues de ambas as línguas, seis falantes brasileiros e oito uruguaios, envolvidos em Tarefas de Leitura e em Testes de Familiaridade Lexical. Com base na literatura disponível, nem sempre específica das variedades em presença, Bruna de los Santos e Ubiratã Alves trabalharam com a hipótese de que a vogal átona final /e/ fosse mais alta, mais centralizada e mais curta no dialeto gaúcho, o que foi confirmado por meio das análises acústicas efetuadas e das comparações estatísticas empreendidas.

Características acústicas da vogal átona final, de Fernanda Lopes e Maria José Vieira, apresenta uma descrição acústica das vogais postônicas finais do falar pelotense. Oito informantes, quatro homens e quatro mulheres, moradores da cidade de Pelotas/ RS, compuseram a amostra coletada. As vogais [a], [i] e [u], na posição postônica final de 72 palavras, foram submetidas aos parâmetros acústicos seguintes: duração absoluta da vogal, duração relativa e valores dos dois primeiros formantes. Os resultados obtidos indicaram que as vogais altas tendem a abaixar enquanto a vogal baixa tende a elevar-se. Além disso, percebeu-se uma centralização da vogal alta posterior. Em relação à duração da postônica, verificou-se que homens de baixa escolaridade produziram as postônicas de forma significativamente mais longa do que homens de alta escolaridade. No grupo das mulheres, houve diferença significativa somente no que diz respeito à duração da vogal baixa.

Vergília Damé e Giovana Ferreira-Gonçalves assinam o artigo A influência da fala na escrita das oclusivas: o papel do VOT em trocas ortográficas. O texto diz respeito às consoantes oclusivas e ao papel da duração do VOT em trocas de cunho ortográfico. Logo, concerne segmentos em que o papel da oralidade necessita ser estabelecido por meio da inspeção acústica dos dados. Tais unidades emergem precocemente na produção oral infantil, mas passam por um longo período de refinamento próprio da articulação, segundo estudos dinâmicos da fala. Na escrita, a maior parte dos segmentos oclusivos 
apresentam uma relação biunívoca entre letra e som, o que não impede a ocorrência de trocas. Estudos sobre esses segmentos reportam erros divididos em três categorias: erros na relação surda/sonora, mudança de ponto de articulação e omissão de letras. Investigando o papel do VOT na ocorrência dessas trocas ortográficas, as autoras identificaram, no VOT das oclusivas dorsais, o par mínimo com maior indício de refinamento articulatório.

O quinto artigo propõe uma investigação de enunciados declarativos extraídos do projeto PRESEEA. Tal projeto visa a disponibilizar um corpus de grande extensão, contendo amostras representativas da diversidade sociolinguística da língua espanhola oral. Análisis sociolingüístico de la entonación en enunciados declarativos del español de Cuba y España: primer acercamiento al corpus PRESEEA, de Adriana Ramírez, Madeleyne Sánchez e Raquel Riverón, põe em foco aspectos linguísticos mais estreitamente ligados à situação comunicativa. Para a realização da descrição e análise da entonação de falantes cubanos e espanhóis, levaram em conta as variáveis sexo e idade, selecionaram gravações de seis informantes, analisaram dez minutos da produção de cada um deles e montaram um corpus contendo 35 unidades declarativas, que foram examinadas acusticamente.

Enfim, no último texto deste dossiê temático, Giovana FerreiraGonçalves, Otávio Pereira e Misael Lemes investigaram a aquisição do rótico retroflexo do inglês por meio de uma ferramenta promissora para a pesquisa linguística e para o ensino-aprendizagem de línguas: o ultrassom. A investigação avaliou a eficácia de sessões de instrução explícita com o intuito de otimizar a aquisição do rótico retroflexo e aprimorar a sua produção. Além do uso do ultrassom como ferramenta de ensinoaprendizagem, os pesquisadores destacaram a possibilidade de, com o seu emprego, melhor descrever, acústica e articulatoriamente, os segmentos róticos. Como o ultrassom é pouco explorado em pesquisas dessa natureza, há pouca informação - na literatura da área - sobre o seu manuseio, a construção de instrumentos de coleta ou de tarefas de ensino, o modo de empregá-lo em descrições linguísticas. Na pesquisa reportada, os autores destacaram que "a instrução explícita, por meio da ultrassonografia, foi fator determinante para a aquisição precoce do segmento retroflexo. Com a mediação de um professor e com acesso aos próprios movimentos articulatórios sendo executados em tempo real, o aluno pôde ser guiado para uma realização mais adequada" de suas produções. É, pois, um campo que promete e cuja exploração inicia. 